\title{
Gentamicin in Urinary Infections of Children
}

\author{
R. J. HOLT and R. L. NEWMAN \\ From Queen Mary's Hospital for Children, Carshalton, Surrey
}

The introduction of polymyxin $B$ methane sulphonate (1961), ampicillin (1961), cephaloridine (1964), and nalidixic acid (1966) has successively narrowed the therapy gap in the treatment of severe chronic urinary infections in children caused by Gram-negative bacilli, though these gains have been partly offset by the marked increase during recent years in the percentage of strains resistant to ampicillin (R. J. Holt and G. T. Stewart, 1968, unpublished observations). Even so, the addition of these new drugs to the established urinary antibiotics and chemotherapeutics has still left a remainder of pathogenic Gram-negative bacilli resistant to the entire available range. Such resistant organisms quite frequently infect the type of case, complicated with congenital anatomical abnormalities, which constitutes a considerable proportion of the patients in this hospital with urinary infections.

Gentamicin is an antibiotic derived from a species of Micromonospora purpurea (Weinstein et al., 1963) and isolated in the research laboratories of the Schering Corporation, New Jersey. Our experience with gentamicin in the treatment of severe systemic infections caused by Gram-negative bacteria (Newman and Holt, 1967) suggested that this antibiotic would be of use in the control of resistant urinary infections. This view was enhanced by our preliminary in vitro studies which showed that gentamicin was active in low concentrations against many strains of enterobacteria and pseudomonads sufficiently resistant to all other likely drugs to suggest that therapy with these agents would be clinically ineffective.

Jao and Jackson (1964) have reported successful results in adults with urinary infections but little work has been done with gentamicin in children. We therefore report here the results of treatment of a series of such refractory cases with gentamicin.

\section{Material and Methods}

The microbiological methods used in the present trial were identical with those detailed in our earlier report

Received November 11, 1967. on the intrathecal administration of gentamicin (Newman and Holt, 1967).

Each infecting organism was isolated in pure culture and was tested against gentamicin discs containing $5 \mu \mathrm{g}$; at the same time the organisms were also tested against the other drugs available for therapy-streptomycin, ampicillin, and tetracycline (all $50 \mu \mathrm{g}$. discs), nalidixic acid (30 $\mu \mathrm{g}$. disc), and nitrofurantoin $(200 \mu \mathrm{g}$. disc). Every attempt was also made to classify the organisms as far as possible, so that strains recovered during or after therapy could be compared with the original isolates. Liquid minimal inhibitory and bactericidal concentrations (MIC and MBC) were determined for each organism, ideally before therapy was started, though in some cases treatment was begun on the basis of disc sensitivity tests.

Gentamicin was assayed in each patient's urine and serum during the course of treatment; assays were performed daily in several cases, but never at intervals of more than 2 or 3 days. The serum assays were facilitated by the fish-spine bead micro-method (Lightbown and Sulitzeanu, 1957), enabling the use of peripheral blood, and were usually collected 1-2 hours after the previous injection. Both serum and urine levels were estimated against standards of gentamicin dissolved in water.

Dose. The standard regimen was $1 \mathrm{mg}$. intramuscular gentamicin/kg. body weight per day, divided into three equal 8-hourly injections. Since gentamicin is supplied in $2 \mathrm{ml}$. ampoules containing $40 \mathrm{mg}$. $/ \mathrm{ml}$., it was necessary to dilute this solution to a dosage suitable for small children; otherwise, with an infant of say $5 \mathrm{~kg}$. body weight, an injection of $0.04 \mathrm{ml}$. would have resulted-a volume below reliable ward measurement. As standard practice, therefore, the $40 \mathrm{mg}$. $/ \mathrm{ml}$. solution was diluted with pyrogen-free water in such a way that an 8-hour dose was always $0.5 \mathrm{ml}$. which was dispensed in $2 \mathrm{ml}$. quantities, each bottle sufficient for one day. In some of the cases the dosage was doubled if the assay results indicated that inadequate levels were being achieved.

Duration of treatment varied according to clinical and bacteriological response, being in most cases between 5 and 10 days. In one case gentamicin was administered for 7 weeks continuously.

Selection of patients. All the patients treated had bacteriological evidence of urinary infection. At least one organism was cultured in heavy growth from the 
TABLE

Sensitivity of Infecting Organisms to Gentamicin

\begin{tabular}{|c|c|c|c|c|c|c|c|c|c|c|}
\hline \multirow{2}{*}{\multicolumn{3}{|c|}{ Organi $3 m^{\star}$}} & \multirow{3}{*}{$\begin{array}{c}\text { No. } \\
20\end{array}$} & & \multicolumn{6}{|c|}{ Gentamicin $(\mu \mathrm{g} . / \mathrm{ml})}$. \\
\hline & & & & & \multirow{2}{*}{$\begin{array}{c}<1 \\
3 \\
1\end{array}$} & \multirow{2}{*}{$\begin{array}{c}1-2 \\
8 \\
3\end{array}$} & \multirow{2}{*}{$\begin{array}{c}2-5 \\
7 \\
8\end{array}$} & \multirow{2}{*}{$\begin{array}{c}5-10 \\
1 \\
3\end{array}$} & \multirow{2}{*}{$\begin{array}{c}10-20 \\
1 \\
4\end{array}$} & \multirow{2}{*}{$\frac{20-50}{\overline{1}}$} \\
\hline Proteus spp. & . &.. & & $\begin{array}{l}\text { MIC } \\
\text { MBC }\end{array}$ & & & & & & \\
\hline Ps. pyocyanea & . & .. & 4 & $\begin{array}{l}\text { MIC } \\
\text { MBC }\end{array}$ & - & $\frac{2}{-}$ & 2 & - & $\overline{3}$ & $\overline{1}$ \\
\hline Esch. coli .. & . & . & 2 & $\begin{array}{l}\text { MIC } \\
\text { MBC }\end{array}$ & $\begin{array}{l}2 \\
1\end{array}$ & $\overline{1}$ & - & $\overline{-}$ & $\overline{-}$ & - \\
\hline Klebsiella .. & .. & .. & 3 & $\begin{array}{l}\text { MIC } \\
\text { MBC }\end{array}$ & $\begin{array}{l}2 \\
2\end{array}$ & $\begin{array}{l}1 \\
1\end{array}$ & - & - & - & - \\
\hline
\end{tabular}

$\star 4$ mixed infections: (1) Proteus and Ps. pyocyanea; (2) Proteus and Esch. coli; (3) Two different strains of Ps. pyocyanea; (4) Esch. coli and Klebsiella.

urine on more than one occasion, and there was supporting evidence of leucocytes and protein in the urine. In several patients mixed infections were treated. Nearly all the patients had spina bifida, and in some there was radiological evidence of urinary tract abnormality, so that recurrent urinary infection with a succession of organisms was likely to occur In view of limited experience with the use of gentamicin in children, the drug was used only in those where the infecting organism showed resistance to other more commonly used drugs. These patients therefore represent the hard core of otherwise untreatable infections. 25 were selected for treatment, from 3 weeks to 10 years of age, mostly under 5 years.

Success or failure of treatment was judged by elimination of the infecting organism without relapse within a reasonable period after treatment was discontinued, though in some 'unsuccessful' cases reinfection with another organism occurred later.

Toxic effects. Toxic effects of gentamicin administration have been reported from some sources. Jao and Jackson (1964) reported vestibular damage, sometimes permanent and often delayed in onset, but this occurred only in patients who received a very large dose or who had deficient renal function. Brayton and Louria (1964) also noted that no such toxic effects were seen in patients with normal renal function, though a rise in blood urea occurred in one patient during treatment; this returned to normal on withdrawing the drug. Jackson (1967) in a survey of reported toxicity concludes that ototoxicity has occurred in a small proportion of patients, usually with deficient renal function and often in association with other ototoxic drugs, but that the incidence of nephrotoxicity is clinically insignificant. Many of the patients in the present series were young babies and subjective evidence of side-effects was difficult to obtain. They were, however, carefully watched for any evidence of untoward effects. Blood urea levels were determined at regular intervals during treatment and the blood picture was also examined frequently. Urines were examined daily for the presence of leucocytes and protein.

\section{Results}

Bacteriological. The organisms involved amounted to 29 strains; 4 of the patients treated had mixed infections. Sensitivity of these strains to gentamicin is shown in the Table.

The MIC of the drug for all these organisms was less than $5 \mu \mathrm{g} . / \mathrm{ml}$., with two exceptions, proteus strains with MIC's of 10 and $20 \mu \mathrm{g} . / \mathrm{ml}$. The MBC's were very little higher, except in the case of Ps. pyocyanea strains, all of which had high MBC/MIC ratios.

Clinical. Of the 25 cases treated, 21 were regarded as successful. In 11 of the successful cases the infecting organism was eliminated within 48 hours, in 16 within 4 days, and in all within 10 days. The bacteriological success of the treatment was in most cases accompanied by marked clinical improvement. There was invariably a fall in the leucocyte count in the urine, often the first sign of response, though usually the proteinuria was slow to subside. Of the 4 cases regarded as failures, 2 were proteus infections and 2 Ps. pyocyanea. These are discussed in detail later.

No adverse reactions were experienced or observed throughout the series. The injections did not appear to be unduly painful and their small volume was welcomed. In no case was there any increase in the blood urea during treatment; in fact in some cases where it was raised at the beginning of treatment it fell noticeably. In one case treatment was begun when the blood urea was $140 \mathrm{mg} . / 100 \mathrm{ml}$. and had been rising steadily for some days. During the first two days of treatment it fell to $40 \mathrm{mg}$. $/ 100$ $\mathrm{ml}$. and remained at about this level thereafter. The blood pictures showed no significant changes except for the subsidence of a leucocytosis where this was present. 


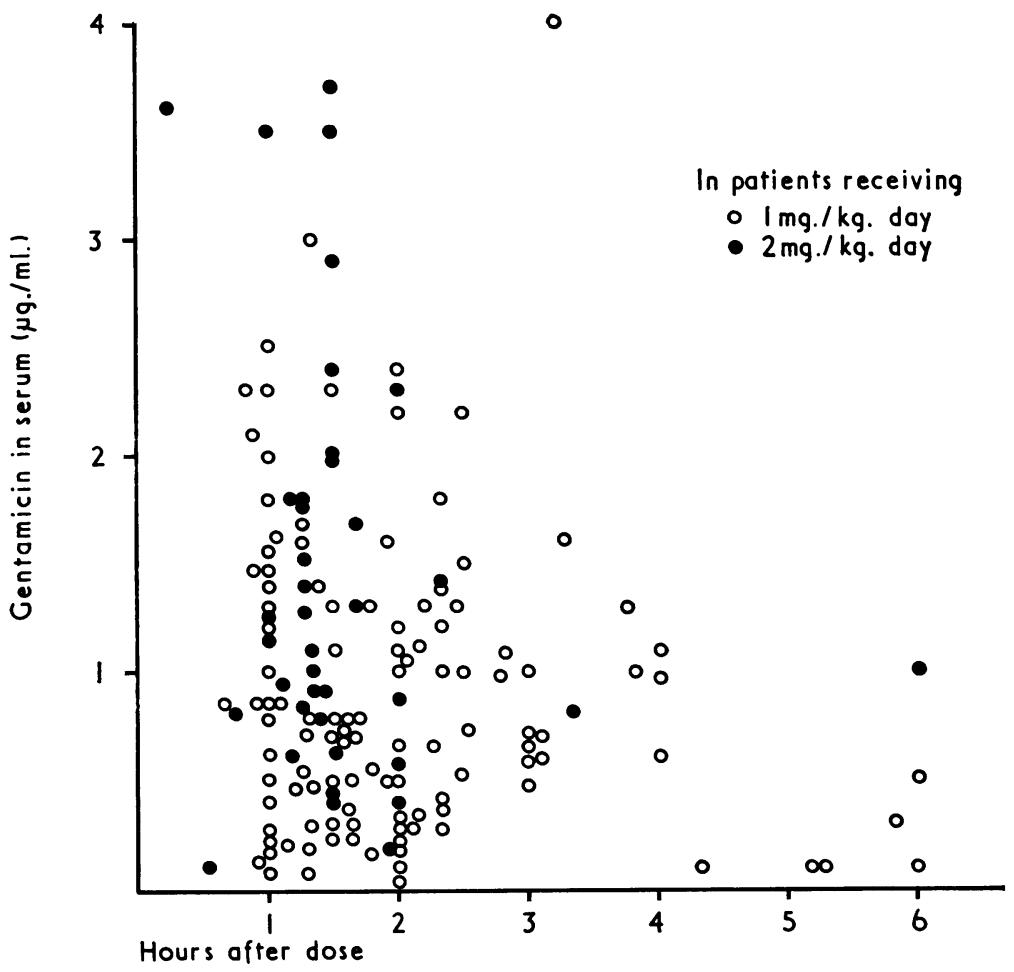

Fig. 1.-Serum levels of gentamicin in patients on two dosage schedules.

Blood and urine levels. Serum levels of gentamicin from patients under treatment are shown in Fig. 1. These never rose above $4 \mu \mathrm{g} . / \mathrm{ml}$. and were usually less than $2 \cdot 5 \mu \mathrm{g} . / \mathrm{ml}$.

Maximum levels were obtained within 1 hour and gradually fell during the subsequent $2-3$ hours: they were mostly between 0.5 and $1.5 \mu \mathrm{g} . / \mathrm{ml}$. in patients receiving $1 \mathrm{mg} . / \mathrm{kg}$. day, and from 0.5 to $2.0 \mu \mathrm{g} . / \mathrm{ml}$. on double dosage. In patients from whom serial specimens were obtained, average levels were reached after the first dose and there did not appear to be any cumulative effect of subsequent doses. It was clear that doubling the dose had an unpredictable effect on the serum levels, though the highest assay results were obtained in those patients on double dosage.

Urine levels of active drug were more consistent, and most of them were between 5 and $30 \mu \mathrm{g} . / \mathrm{ml}$. on single doses, though a few ranged from very low levels up to $120 \mu \mathrm{g}$./ml., in one case up to $200 \mu \mathrm{g}$. $/$ $\mathrm{ml}$. On double dosage the urine levels were more scattered but in general were higher than on single dosage (Fig. 2).
Four failed cases. In four patients in this series the infecting organisms were not eliminated by the drug.

Case 1. A boy of 4 years, with a meningomyelocele and recurrent urinary infection, was treated at $1 \mathrm{mg}$. $/ \mathrm{kg}$. day for a proteus infection. The $\mathrm{MBC}$ was $1-2 \mu \mathrm{g} . / \mathrm{ml}$. and the MIC 5-10 $\mu \mathrm{g} . / \mathrm{ml}$. Urine levels of the drug were poor (about $20 \mu \mathrm{g}$. $/ \mathrm{ml}$.) and the dose was doubled after 5 days. By then the $\mathrm{MBC}$ had risen to $20 \mu \mathrm{g}$. $/ \mathrm{ml}$. and the organism was still present. Doubling the dose had no effect on the urinary levels of the drug and after another 5 days the treatment was changed. Gentamicin levels in the serum were also very poor in this case ( $<1 \mu \mathrm{g} . / \mathrm{ml}$. ).

Case 2. A baby of 1 year with a similar case history and a proteus infection (MIC 2-5, MBC 2-5 $\mu \mathrm{g}$. $/ \mathrm{ml}$.) was treated with $1 \mathrm{mg} . / \mathrm{kg}$. day. Urine levels were good to begin with (about $50 \mu \mathrm{g} . / \mathrm{ml}$.) but rapidly fell to $10-15 \mu \mathrm{g} . / \mathrm{ml}$., and the organism continued to grow heavily on culture. Re-isolates during treatment showed an $\mathrm{MBC}$ of $10 \mu \mathrm{g} . / \mathrm{ml}$. and treatment with gentamicin was abandoned Again, serum levels of the drug were very low $(<0.5 \mu \mathrm{g} . / \mathrm{ml}$.). 


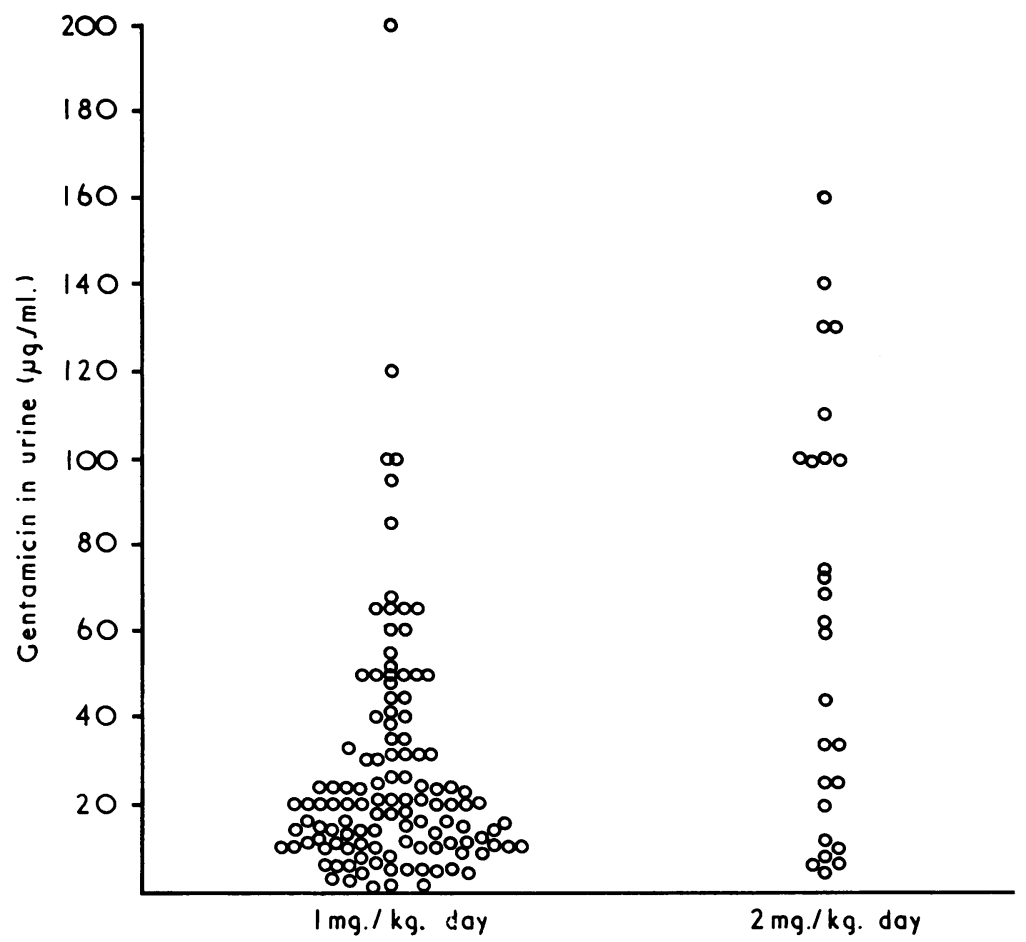

FIG. 2.-Urine levels of gentamicin in patients on two dosage schedu'es.

Case 3. A boy of 8 with recurrent urinary infections had a mixed infection with proteus and Ps. pyocyanea. Treatment at $1 \mathrm{mg} . / \mathrm{kg}$. day quickly eliminated the proteus but the Ps. pyocyanea persisted in spite of high urinary levels $(50 \mu \mathrm{g} . / \mathrm{ml}$.), well above the original $\mathrm{MBC}$ of 10-20 $\mu \mathrm{g} . / \mathrm{ml}$. Re-isolates of the organism, however, showed an increasing MBC over $50 \mu \mathrm{g} . / \mathrm{ml}$., and doubling the dose failed to increase the urine levels sufficiently to eliminate it.

Case 4. A baby of 9 months had a mixed urinary infection with Esch. coli and $K l$. aerogenes. These organisms were eliminated within 48 hours of treatment but were replaced by a strain of Ps. pyocyanea sensitive to gentamicin. Treatment continued but the urine levels barely exceeded the MBC of $2-5 \mu \mathrm{g} . / \mathrm{ml}$. and the dose was doubled. The urine levels then rose to the 50-100 $\mathrm{g}$. $/ \mathrm{ml}$. range, but the MBC for the Ps. pyocyanea also rose similarly and the organism was not eliminated.

\section{Discussion}

Clinical results in these patients have corresponded well with the bacteriological findings in vitro. In most cases a satisfactory level of the drug has been easily maintained in the urine, with elimination of the infection. In 3 of the 4 who did not respond to treatment, this was probably due to failure to achieve a bactericidal level in the urine and it is difficult to find a reason for this. Jao and Jackson (1964) found in adults that urinary concentrations of the drug depended on urinary output, but these children were not passing unusually large volumes of urine. The ability of some organisms to develop resistance to the drug very quickly was also demonstrated in these 4 patients, and it seems likely that this, in combination with poor or subinhibitory levels in the urine, accounted for the failures.

It appears from the wide variations in blood levels of gentamicin that absorption and excretion rates may vary in children more than in adults. While blood levels in this series agree largely with those of other authors, we have been unable to show a close correlation between dosage and blood levels; the slow rise in blood levels at the beginning of treatment noticed by Jao and Jackson has not been evident.

Vestibular damage from gentamicin reported by other workers was often delayed in onset and was in many cases permanent. Such damage nearly always occurred in patients with deficient renal function which may have led to abnormally high blood levels of the drug. In some urinary infections higher dosage than usual may be necessary if adequate urinary levels are to be achieved quickly 
and maintained. Furthermore, the blood levels found in this series would in the main be too low to deal with a systemic or tissue infection and larger doses would be essential. Higher blood levels in such circumstances may approach a toxic concentration, and it is evident that until much more information is available regarding absorption and excretion of the drug it is essential that serum assays are carried out during treatment of children. It is difficult to specify a maximum safe blood level above which toxic effects might be expected. It appears, however, that a limit of $10 \mu \mathrm{g} . / \mathrm{ml}$. might be adopted for the time being. None of the cases in this series has shown any evidence of toxic effects, and these do not appear likely to occur at blood levels such as we have found.

A noteworthy feature of this series is the rapidity with which most cases responded to treatment. $75 \%$ of infections were eliminated within 4 days. In those which persisted for up to 10 days no appreciable increase in resistance of the organisms was seen on re-isolation, though this did occur in the cases which failed to respond. Failure to sterilize the urine within 4 days calls for a check on the sensitivity of the organism with a view to increasing the dose if necessary. In most cases a course of treatment lasting 5-7 days should be embarked upon and extended when appropriate. No evidence was seen in this series of accumulation of the drug in the body and no reason for restricting the duration of treatment, but in the present state of knowledge of gentamicin prolonged courses of treatment should be very strictly supervised.

Success in eliminating the infection in such a high proportion of difficult cases suggests that gentamicin is a useful drug for the treatment of selected cases of this kind.

\section{Summary}

Twenty-five children with urinary infections were treated with gentamicin; in almost every case the infecting organism or organisms had been found to be resistant in vitro to all other drugs available, but sensitive to gentamicin. 21 showed bacteriological clearance of the infection, accompanied by improvement of other symptoms, often in an unexpectedly short time. The results of repeated serum and urine assays of gentamicin are reported; 4 cases were regarded as failures, and possible reasons for this are discussed. No toxic effects attributable to the drug were seen in any child treated.

Thanks are due to the consultant staff of this hospital who kindly allowed their patients to be treated in this trial, and to the ward sisters and staff who co-operated in the collection of specimens. We are also indebted to $\mathrm{Mr}$. Frankcombe and his staff in our routine microbiology laboratories. 'Genticin' was supplied by British Schering Ltd. whose help, particularly from Dr. I. Jamieson and Mr. D. R. Lewis, is appreciated.

\section{REFERENCES}

Brayton, R. G., and Louria, D. B. (1964). Gentamycin in gramnegative urinary and pulmonary infections. Arch.intern.Med., 14, 205.

Jackson, G. G. (1967). Gentamicin. Practitioner, 198, 855.

Jao, R. L., and Jackson, G. G. (1964). Gentamicin sulfate, new antibiotic against gram-negative bacilli. f. Amer. med. Ass., 189, 817.

Lightbown, J. W., and Sulitzeanu, D. (1957). The assay of penicillin in blood serum using Sarcina lutea. Bull. Wld Hlth Org., $17,553$.

Newman, R. L., and Holt, R. J. (1967). Intrathecal gentamicin in treatment of ventriculitis in children. Brit. med. F., 2, 539.

Weinstein, M. J., Luedemann, G. M., Oden, E. M., and Wagman, G. H. (1963). Gentamicin, a new broad-spectrum antibiotic complex. Antimicrob. Agents Chemother., 3, 1. 